\title{
Effects of Job Organizational Culture, Benefits, Salary on Job Satisfaction Ultimately Affecting Employee Retention
}

\author{
Shuja Iqbal*, Li Guohao and Shamim Akhtar
}

School of Management, Jiangsu University, Zhenjiang, P.R. China

\begin{abstract}
Employee retention is very critical issue these days. Cost of losing talented, experienced and skilled workers is much higher then the cost of hiring new ones. Therefore, it is more critical for the organizations to retain their best talent with them. In this study a relationship is developed between job satisfaction, organization culture, benefits and salary to check their influence on employee retention. The relatedness of these variables with the motivational theories has also been measured. Employee retention is critical in today's competitive advantage. Job satisfaction is the key variable which makes the higher or lower levels of employee retention at any organization. Moreover, organizational culture also plays an effective role in retaining the best talent within the organization. As loyalty and strategic commitment among all employees regardless of job can be enhanced through the organizational cultures as it emphasizes on teamwork, security and respect of individual employees.
\end{abstract}

Besides this, benefits and salary are also strong determinant of employee retention at organization. There is a significant relationship between rewards offered by a firm and employee satisfaction for the employees to work for the organizations for longer time duration. High level of pay and benefits as compare to other companies in the market, attract and retain high quality employees. Thus, these elements are directly related to employee retention at any organization.

Keywords: Organizational culture; Salary; Benefits; Job satisfaction; Employee retention; Rewards

\section{Introduction}

\section{Research objectives}

Employee retention is the main consideration of human resource (HR) debate nowadays rather than recruiting effectively. The main objective of this study is to check the effects of organizational culture, benefits and salary on job satisfaction to find the ultimate effect on employee retention. The study focuses to check the effects of above mentioned factors on both the employees from education and industrial sector. In order to, find out the most crucial factors in employee retention to raise or reduce them accordingly. It will result in cost saving, knowledge enhancement, skilled workers, productivity and the good will of the company.

\section{Problem Statement}

1: Does organization culture have positive and significant effect on job satisfaction leading to employee retention?

2: Does other benefits and salary have positive and significant impact on job satisfaction?

3: Does job satisfaction have positive and significant impact on employee retention in both educational and industrial sector?

\section{Significance of Study}

This research study is very important in terms of topic and the variables selected for the model. Because all the factors like organizational culture, benefits and salary are affecting job satisfaction directly and in result employee turnover rate decreases or increases. This study is unique in terms of the variable selection and intermediation of job satisfaction. The accurate result calculation has defined the purified results.

The results show the equal importance of organizational culture, benefits and salary to increase job satisfaction which ultimately increases the employee retention rates in education and industrial sector. These results can provide help to implement the reward system, salary attractive packages and good organizational culture to retain the experienced workers with the organization.

This paper will significantly contribute to the applied business research with aid of empirical findings which were not yet explored altogether in one model. Thus, it will open avenues for further research dimensions and provide practical approach and implications for the real-world scenarios. The variables used in the proposed model are diverse and integrated in a way to have interesting findings in this competitive area of research.

\section{Relatedness to Motivational Theories}

\section{Job satisfaction}

Psychologist Abraham Maslow first introduced his concept of a hierarchy of needs in 1943 paper "A Theory of Human Motivation" and his subsequent book Motivation and Personality. This hierarchy suggests that people are motivated to fulfill basic needs before moving on to other, more advanced needs. This hierarchy is most often displayed as a pyramid. The lowest levels of the pyramid are made up of the most basic needs, while the more complex needs are located at the top of the pyramid.

This theory is highly related to the job satisfaction at workplace if employees are satisfied by accomplishing each step of this pyramid they will be at the peak of employer loyalty and will retain with the

*Corresponding author: Shuja Iqbal, School of Management, Jiangsu University, Zhenjiang, P.R. China, Tel: +8618605240210, Email: shujaiqbal88@hotmail.com

Received November 01, 2017; Accepted November 08, 2017; Published November 18, 2017

Citation: Iqbal S, Guohao L, Akhtar S (2017) Effects of Job Organizational Culture, Benefits, Salary on Job Satisfaction Ultimately Affecting Employee Retention. Review Pub Administration Manag 5: 229. doi:10.4172/2315-7844.1000229

Copyright: (c) 2017 lqbal S, et al. This is an open-access article distributed under the terms of the Creative Commons Attribution License, which permits unrestricted use, distribution, and reproduction in any medium, provided the original author and source are credited. 
organization for longer time spans. All the levels of Maslow's theory are directly related to the fulfillment of the needs and wants of employees, which force them to be happy and staying with the organization.

\section{Organizational culture}

Greet Hosted proposed a systematic framework for assessing and differentiating national cultures in relation to organizational culture known as the cultural dimensions theory. He gathered and analyzed extensive data on the world's values and cultures, particularly through the IBM survey study, in order to build a comprehensive model which argues that people differ across on the extent to which they endorse six dimensions of values - power (equality versus inequality), collectivism versus individualism, uncertainty avoidance versus tolerance, masculinity versus femininity, temporal orientation, and indulgence versus restraint. These cultural dimensions can help organizations to develop an atmosphere where the employees can feel more energized and satisfied so that they should remain with the organizations for long term. The main elements of this model are linked to this study as following:

\section{Power distance index (PDI)}

"Power distance is the extent to which the less powerful members of organizations and institutions (like the family) accept and feels that power is distributed unequally." Cultures that endorse high power distance accept power relations that are less consultative or democratic. People relate to one another more as equals regardless of formal positions. Subordinates are more comfortable with, demand the right to contribute to and critique the decision making of those in power. In this kind of organizations job satisfaction is high which ultimately leads to the high employee retention. In high power distance organizations, less powerful accept power relations that are more autocratic and paternalistic. Subordinates acknowledge the power of others simply based on where they are situated in certain formal, hierarchical positions. This type of organizations provides lower levels of job satisfaction which tends to decrease the employee retention.

Individualism (IDV) vs. collectivism: The degree to which individuals are integrated into groups is called collectivism. In individualistic organizations, the stress is put on personal achievements and individual rights. People are expected to stand up for themselves and their immediate family, and to choose their own affiliations. Organizations following this approach do not have long term relationships with their employees. The atmosphere of individual success, feeling of jealousy tends to unrest between employee relations which creates job dissatisfaction. In contrast, in collectivist societies, individuals act predominantly as members of a life-long and cohesive group or organization. People have large extended families, which are used as a protection in exchange for unquestioning loyalty.

\section{Uncertainty avoidance index (UAI)}

An organization's tolerance for uncertainty and ambiguity is called the uncertainty avoidance. It reflects the extent to which employees of an organization attempt to cope with anxiety by minimizing uncertainty. Employees in cultures with high uncertainty avoidance tend to be more emotional. They try to minimize the occurrence of unknown and unusual circumstances and to proceed with careful changes step by step with planning and implementing rules, laws and regulations. In contrast, low uncertainty avoidance cultures accept and feel comfortable in unstructured situations or changeable environments and try to have as few rules as possible. Employees in these cultures are more pragmatic, they are more tolerant of change and the retention rates are higher in these organizations.

Masculinity (MAS), vs. femininity: Masculine cultures' values are competitiveness, assertiveness, materialism, ambition and power, whereas feminine cultures place more value on relationships and quality of life. In masculine cultures, the differences between gender roles are more dramatic and less fluid than in feminine cultures where men and women have the same values emphasizing modesty and caring. As a result of the taboo on sexuality in many cultures, particularly masculine ones, and because of the obvious gender generalizations implied by Hofstede's terminology, this dimension is often renamed by users of Hofstede's work, e.g. to quantity of life vs. quality of life.

Long term orientation (LTO), vs. short term orientation: First called "Confucian dynamism", it describes societies' time horizon. Long term oriented societies attach more importance to the future. They foster pragmatic values oriented towards rewards, including persistence, saving and capacity for adaptation. In short term oriented societies, values promoted are related to the past and the present, including steadiness, respect for tradition, preservation of one's face, reciprocation and fulfilling social obligations.

Benefits and salary: Henry Herzberg's theory of motivation is related to these two factors for employee retention at any organization. This theory is sometimes called two factor theories. He looked the motivating factors and hygiene factors. Hygiene factors are also called dis satisfiers like less pay according to education of individual which do not match with his/her skills or expertise. Not sufficient and favorable physical environment, no proper or good system or rewards or benefits etc.

The motivators are called as satisfiers which increases the job satisfaction like, competitive salary packages, attractive and appealing reward system, these are the key motivators at any company which motivates employees to do their work more enthusiastically and leads to employee retention.

\section{Employee retention}

Global economy is known by continuous change, because of mergers, acquisitions, downsizing and breach of trust. We have noticed one important shift in human resource demand in recent years. It is now focused to develop human resource initiatives to address retention issues. Several important factors are involved in this shift; the reality that many employees focus on short-term benefits instead of life long thought of organizational commitment. Increasing needs to find employment opportunities, which provide a constructive environment to effectively use the abilities, skills and interests (Duggan CHRP).

Today's competitive advantage to organizations is to retain and engage the high potential talent. Human resource department is now in action to retain employees through making the policies for employee betterment, so employee feel satisfied and stay for longer time period with the organization. It is also the retention of valued skills. If a company retains its employees it will increase the communication, employee commitment and workforce support for the organization. The number of employees leaving organizations is larger than the number joining the organizations. Shortage of labor will result in war of talent in near future. There are many options for talented people so organizations always try to retain them [1] when a company loses employees it loses the skills, knowledge, and "corporate memory". The overall size of these losses in the crucial management issues, directly impact the productivity, profitability and product and service quality. High turnover can negatively affect the employment relationship, 
moral and work place safety. Businesses have to bear high cost of hiring new employees, the difficulties linked with finding and training new employees can be large, the particular work place required skills and knowledge workers who has moved can take years to replace.

Employee retention is the most serious problem faced by the organizational leaders' due to many reasons like shortage of skilled labor, economic growth and employee turnover. Handling employee turnover is a serious issue for organizations as different organizations use different approaches to retain their employees. Organization's human resource strategies consider retention as their overall module. It starts with hiring new and right people and putting efforts to keep them engaged and loyal to the organization. Nowadays worker's demands are much more than earlier. It is in many aspects not only regarding salaries and benefits but also the work experience and the cultural context in which it occurs. The dynamic work environment can be a critical strength to attract and retain valuable employees. It is important to realize the different needs and wants of employees to schedule an effective retention plan for toady's employment market. If the retention strategies are not properly designed all the efforts from the hiring of employees will ultimately become useless [2]. Retention is defined as "the ability to hold onto those employees you want to keep, for longer than your competitors".

\section{Job satisfaction}

The element "job satisfaction" is concerned for both employees of the organizations and the people who study them. This variable is frequently studied for organizational behavior. Job satisfaction is major concern for organizational research but also very important for employee performance and employee satisfaction. The feelings of employees what they perceive, what are their experiences at job either positive or negative, all these factors influence employee satisfaction in the organization [1].

Job satisfaction can also be explained as "the agreeable emotional condition resulting from the assessment of one's job as attaining or facilitating the accomplishment of one's job values" [3]. It also depends on variety of factors such as pay practices, the relationship of employee to supervision, work environment; increased productivity is associated with higher job satisfaction, lower absenteeism and lower turnover. Wong discovers the influence of job satisfaction on intention to change jobs among secondary school teachers in Hong Kong. His study affirms that low job satisfaction in teachers' tend to have low level of commitment and productivity. Moreover, teachers responded that they are prepared to leave teaching if a job alternative which offers a higher salary became available. Glance, Hogg and Huberman [4] mentioned the relationship between turnover and productivity asserted that the lower turnover is positively correlated with productivity.

Amah stressed that job satisfaction was found to have a direct negative relationship with turnover intention. These results indicate that the effect of job satisfaction on turnover can be enhanced in two ways; namely, when employees find congruence between their job and their self-identity, and when involvement in such jobs enhances their overall life satisfaction. On the other hand, turnover can be considered as cost of running a business [5].

Job satisfaction and dissatisfaction depends upon the expectation of employee that what this job will supply them. Failure of organizations to keep competent employees will lead them to dissatisfaction and ultimately will hamper the organization's productivity and quality. To keep the employees intact with their job dissatisfaction is an important factor to increase the employee failure rate at any organization.
Employee's commitment with their jobs and to satisfy with their work structure is an important determinant. Job satisfaction also affects the quality of service provided by the employees. According to Al-Hussami the low wages and less job satisfaction are the major components that are affecting the retention [1].

Job satisfaction is complex phenomenon with multi facets (Fisher and Locke; Xie and Johns), it is influenced by the factors like salary, working environment, autonomy, communication, and organizational commitment many researchers identify in several ways in definition of job satisfaction. Greenberg and Baron define job satisfaction as an individual's cognitive, affective, and evaluative reactions towards his or her job. Strong and valuable loyalty with the organization is developed by the employees who are satisfied with their jobs and they intend to serve the organization for longer duration at the workplace [6].

Organizational culture: Interaction between people at all levels defines the organization's culture and this interaction also defines the organization's attitude towards its people and process. Normally cultural issues lead people to leave organizations (Duggan CHRP). Variation in employee retention at different organizations may be the resultant of organizational cultural values. These values affect that organization's human resource strategies, development and promotion procedures, and reward systems. In different organizations the different levels of commitment and retention among employees, are fostered by psychological contracts which are the resultant of different human resource strategies. This can also moderate the gap between retention rates of weak and strong performers [7].

Loyalty and strategic commitment among all employees regardless of job can be enhanced through the organizational cultures which focus on teamwork, security and respect of individual employees. On other hand, the organizations which emphasis on values like individual initiatives and individual rewards for achieving particular work tasks, these values foster entrepreneurial norms and attitudes. Employees do not show their loyalty because organizations do not provide them long term security. And the weaker performers will leave such kind of environment soon and the rest will stay in order to "exploit the organization until better rewards could be gotten elsewhere". An atmosphere where resources to work were provided nicely with flexible working environment created the employee retention. A factor of fun or enjoyment at workplace may be helpful to increase the job satisfaction among employees [8].

\section{Benefits}

There employees who are motivated by rewards offered by the firm they tend to work for the organizations for long term or to continue their work for industry. In recent years rewards got importance due the economic conditions of both the employees and the organizations. It is very important factor for retaining employees as well for job satisfaction [1]. The rewards are very significant and wished by the employees to be given them on special contributions and performance made by them. It can be internal or external like it can be cash, in the forms of bonuses or some recognizing some employee name of the month [2].

Viable compensation and benefit packages including salary, bonuses, stock options, and the traditional health insurance and retirement packages are tools that some companies use to help keep employees retained. Bonus or profit sharing programs which are developed carefully provide encouraging, goal-oriented initiatives for employees to aim towards. The objectives for achievement set out by the manager and the employee are more achievable if sensible and useful incentives are offered. Benefit programs are worthy to employees 
because benefits can broaden beyond the traditional health insurance and retirement programs and can include:

- Employees feel respected, valued, and appreciated

- Employees get to be players and not just hired hands

- Employees get to make a difference

Attractive non-monetary benefits and recognition programs can be powerful tools. Increasingly, companies are using informal methods for rewarding staff while financial compensation is becoming less the norm for valuing employee activities. Reward systems that are personbased proving to be successful especially when recognition is linked to personal needs or wants such as

- Time off

- Flexible work hours

- Job-sharing

- Office space

- Home office

- Special projects, committee Involvement

- Public acknowledgment

- Career development and training

- Company organized discounts such as fitness memberships, discounts on company products/services, discounts on client's products/services

- Community and charity involvement

One of Fortune's 2001 "100 Best Companies to Work for in America" companies have established the "Head start for the Holidays" program which matches up company employees with hundreds of needy children over the holidays [2].

\section{Salary}

The factor of pay is about $31.8 \%$ for employee retention at any organization (Nowack). One of the human resource management practices is the pay practice which deals with pay normally, wage, salary and benefits etc. it has an important role in implementation strategies. High level of pay and benefits as compare to other companies in the market, attract and retain high quality employees. But this might have a negative impact on company's overall labor costs. Pay practice is very important factor for companies to hire and retain high quality employees from the level of applying for the job. While on the other hand employees also have to work hard to maintain their high level of performance otherwise they will lose their work. It also has some correlation with job satisfaction. As supported by Ting [9] declares the significant of pay that it is strong determinant of job satisfaction. Moreover, he explains two different type of pay practices effect on job satisfaction; satisfaction with pay itself and satisfaction with financial prospects in the upcoming. There is a longstanding interest of two items which are correlated with job satisfaction.

To enhance employee motivation which will increase the employee productivity, the relationship between pay practice and job satisfaction is very important. According to wage efficiency theories states that paying high can increase the productivity sometimes. As it has a great effect on employee turnover. These theories state that this is not easy for the employees receiving high pay to leave their jobs. Indeed, the relationship between pay practices and job satisfaction in efficiency wage theories is confusing. There are some diverse studies such as Steijin inspect the overall job satisfaction of Dutch public workers with respect to their pay. The results show that there is positive effect of the existence of HRM practice which refers to pay practice on the job satisfaction. Likewise, Bradley, Petrescu and Simmons observe the impact of human resource management practices and pay inequality on workers' job satisfaction [5]. But simultaneously some other factors also affect professional employee retention like gender and marital status, some market factors like labor supply and initial salary level.

\section{Hypothesis}

H1: Organization culture has positive and significant effect on job satisfaction leading to employee retention?

H2: Other benefits and salary have positive and significant impact on job satisfaction?

H3: Job satisfaction has positive and significant impact on employee retention (Figure 1).

\section{Methodology}

\section{Random sampling technique}

A simple random is a technique from which a sample of size $n$ drawn from a population of size $\mathrm{N}$ in such a way that every possible sample of size $\mathrm{n}$ has the same chance of being selected. In this technique sample is selected truly on the bases of random selection.

\section{Why random sampling}

Random sampling is commonly used for data gathering for being much easier. It is selected so that random representatives of high, middle and lower level employees can respond to the questionnaires by their will. So, they can provide fair results without biasness, that they were not forced to provide information.

\section{Data collection sources}

Data has been collected through questionnaires. The questionnaires were distributed by the representatives of different educational Institutions and factories. The data has been collected form government and private sector organizations and universities in Pakistan in the year 2015.

\section{Response rate}

The response rate was $50 \%$. Out of 300 only 152 questionnaires were received completely filled. The respondents include the top management, middle management, lower management, lecturers, professors, principles and other administrative staff.

\section{Data analysis}

Data has been analyzed for correlations and regression between

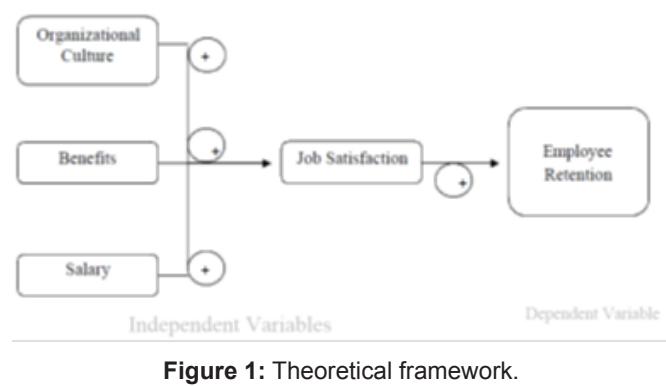


Citation: Iqbal S, Guohao L, Akhtar S (2017) Effects of Job Organizational Culture, Benefits, Salary on Job Satisfaction Ultimately Affecting Employee Retention. Review Pub Administration Manag 5: 229. doi:10.4172/2315-7844.1000229

Page 5 of 7

the independent variables; organizational culture, benefits and salary, the intermediating variable job satisfaction and the dependent variable employee retention.

\section{Results}

The data analysis showed the following results:

\section{The responses for job satisfaction from 1-2}

The results of the responses of job satisfaction from 1-2 shows that organizational culture, benefits and salary has no effect on job satisfaction. Therefore, employee retention has also no effect due to these variables because there is no job satisfaction at all. The results were completely insignificant. In this case all three hypotheses are rejected because all three variables have no positive relation with job satisfaction (Table 1).

\section{The response for job satisfaction from 2.1-3}

The results of the responses from 2.1 to 3 have shown some level of significance. It means that organizational culture and salary has impact on job satisfaction whereas benefits have no impact on job satisfaction. So, the employee retention is affected by the job satisfaction is affected to some extent. In this case hypothesis H I and H III are accepted to some extent due to the significance level of the results and hypothesis H II has been rejected due to negative relation with job satisfaction (Table 2).

\begin{tabular}{|c|c|c|c|c|}
\hline \multicolumn{4}{|c|}{ Model Summary } \\
\hline Model & R & R Square & Adjusted R Square & Std. Error of the Estimate \\
\hline 1 & $0.343^{\mathrm{a}}$ & 0.118 & -0.086 & 0.76986 \\
\hline
\end{tabular}

a. Predictors: (Constant), salary, Benefits, O. Culture

ANOVA $^{\text {b }}$

\begin{tabular}{|c|c|c|c|c|c|}
\hline Model & Sum of Squares & Df & Mean Square & F & 0.580 \\
\hline Regression & 1.030 & 3 & 0.343 & - \\
\hline Residual & 7.705 & 13 & 0.593 & - \\
\hline Total & 8.735 & 16 & - & - \\
\hline
\end{tabular}

a. Predictors: (Constant), salary, Benefits, O. Culture

b. Dependent Variable: Retention

\begin{tabular}{|c|c|c|c|c|c|}
\hline \multicolumn{6}{|c|}{ Coefficients $^{a}$} \\
\hline \multicolumn{3}{|c|}{ Unstandardized Coefficients } & \multicolumn{3}{|c|}{ Standardized Coefficients } \\
\hline Model & B & Std. Error & Beta & $\mathbf{t}$ & Sig. \\
\hline (Constant) & 2.336 & 1.372 & - & 1.703 & 0.112 \\
\hline O. Culture & -0.181 & 0.498 & -0.095 & 0.363 & 0.723 \\
\hline Benefits & -0.094 & 0.251 & -0.098 & -0.376 & 0.713 \\
\hline Salary & 0.362 & 0.289 & 0.329 & 1.254 & 0.232 \\
\hline
\end{tabular}

a. Dependent Variable: Retention

\begin{tabular}{|c|c|c|c|c|c|}
\hline \multicolumn{6}{|c|}{ Correlations } \\
\hline \multicolumn{3}{|c|}{ O. Culture } & Benefits & Salary & Retention \\
\hline \multirow{3}{*}{ O. Culture } & Pearson Correlation & 1 & 0.027 & 0.092 & -0.067 \\
\hline & Sig. (2-tailed) & - & 0.918 & 0.725 & 0.798 \\
\hline & $\mathrm{N}$ & 17 & 17 & 17 & 17 \\
\hline \multirow{3}{*}{ Benefits } & Pearson Correlation & 0.027 & 1 & 0.053 & -0.083 \\
\hline & Sig. (2-tailed) & 0.918 & - & 0.841 & 0.750 \\
\hline & $\mathrm{N}$ & 17 & 17 & 17 & 17 \\
\hline \multirow{3}{*}{ Salary } & Pearson Correlation & 0.092 & 0.053 & 1 & 0.315 \\
\hline & Sig. (2-tailed) & 0.725 & 0.841 & - & 0.219 \\
\hline & $\mathrm{N}$ & 17 & 17 & 17 & 17 \\
\hline \multirow{3}{*}{ Retention } & Pearson Correlation & -0.067 & -0.083 & 0.315 & 1 \\
\hline & Sig. (2-tailed) & 0.798 & 0.750 & 0.219 & - \\
\hline & $\mathrm{N}$ & 17 & 17 & 17 & 17 \\
\hline
\end{tabular}

Table 1: The responses for job satisfaction from 1-2.

\begin{tabular}{|c|c|c|c|c|c|}
\hline \multicolumn{6}{|c|}{ Correlations } \\
\hline \multicolumn{3}{|c|}{ O. Culture } & Benefits & Salary & Retention \\
\hline \multirow{3}{*}{ O. Culture } & Pearson Correlation & 1 & $0.488^{* *}$ & $0.316^{*+}$ & $0.372^{* *}$ \\
\hline & Sig. (2-tailed) & - & 0.000 & 0.002 & 0.000 \\
\hline & $\mathrm{N}$ & 90 & 90 & 90 & 90 \\
\hline \multirow{3}{*}{ Benefits } & Pearson Correlation & $0.488^{* *}$ & 1 & $0.436^{*+}$ & $0.396^{*+}$ \\
\hline & Sig. (2-tailed) & 0.000 & & 0.000 & 0.000 \\
\hline & $\mathrm{N}$ & 90 & 90 & 90 & 90 \\
\hline \multirow{3}{*}{ Salary } & Pearson Correlation & $0.316^{* *}$ & $0.436^{*+}$ & 1 & $0.477^{*+}$ \\
\hline & Sig. (2-tailed) & 0.002 & 0.000 & - & 0.000 \\
\hline & $\mathrm{N}$ & 90 & 90 & 90 & 90 \\
\hline
\end{tabular}


Citation: Iqbal S, Guohao L, Akhtar S (2017) Effects of Job Organizational Culture, Benefits, Salary on Job Satisfaction Ultimately Affecting Employee Retention. Review Pub Administration Manag 5: 229. doi:10.4172/2315-7844.1000229

Page 6 of 7

\begin{tabular}{l|c|c|c|c|c|}
\multirow{3}{*}{ Retention } & Pearson Correlation & $0.372^{* *}$ & $0.396^{* *}$ & $0.477^{* *}$ & 0.000 \\
\cline { 2 - 5 } & Sig. (2-tailed) & 0.000 & 0.000 & 90 & 90 \\
\cline { 2 - 6 } & $\mathrm{N}$ & 90 & 90 & 90 \\
\hline
\end{tabular}

Correlation is significant at the 0.01 level (2-tailed)

Model Summary

\begin{tabular}{|c|c|c|c|}
\hline $\mathbf{R}$ & R Square & Adjusted R Square & Std. Error of the Estimate \\
\hline $0.545^{\mathrm{a}}$ & 0.297 & 0.273 & 0.69993 \\
\hline
\end{tabular}

a. Predictors: (Constant), salary, O. Culture, Benefits

ANOVA $^{\text {b }}$

\begin{tabular}{|c|c|c|c|c|}
\hline Model & Sum of Squares & Df & Mean Square & Sig. \\
\hline Regression & 17.824 & 3 & 5.941 & 12.128 \\
\hline Residual & 42.132 & 86 & 0.490 & - \\
\hline Total & 59.956 & 89 & - & - \\
\hline
\end{tabular}

a. Predictors: (Constant), salary, O. Culture, Benefits

b. Dependent Variable: Retention

Coefficients

\begin{tabular}{|c|c|c|c|c|c|}
\hline \multicolumn{3}{|c|}{ Unstandardized Coefficients } & \multicolumn{3}{|c|}{ Standardized Coefficients } \\
\hline Model & B & Std. Error & Beta & $\mathbf{t}$ & Sig. \\
\hline (Constant) & 0.223 & 0.504 & - & 0.443 & 0.659 \\
\hline O. Culture & 0.356 & 0.199 & 0.187 & 1.786 & 0.078 \\
\hline Benefits & 0.165 & 0.119 & 0.152 & 1.380 & 0.171 \\
\hline Salary & 0.457 & 0.132 & 0.352 & 3.470 & 0.001 \\
\hline
\end{tabular}

Table 2: The response for job satisfaction from 2.1-3.

\begin{tabular}{|c|c|c|c|c|c|}
\hline \multicolumn{6}{|c|}{ Correlations } \\
\hline \multicolumn{3}{|c|}{ O. Culture } & Benefits & Salary & Retention \\
\hline \multirow{3}{*}{ O. Culture } & Pearson Correlation & 1 & $0.579^{* *}$ & $0.574^{\star *}$ & $0.487^{* *}$ \\
\hline & Sig. (2-tailed) & - & 0 & 0 & 0.001 \\
\hline & $\mathrm{N}$ & 44 & 44 & 44 & 44 \\
\hline \multirow{3}{*}{ Benefits } & Pearson Correlation & $0.579^{* *}$ & 1 & $0.654^{\star *}$ & $0.579^{* *}$ \\
\hline & Sig. (2-tailed) & 0 & - & 0 & 0 \\
\hline & $\mathrm{N}$ & 44 & 44 & 44 & 44 \\
\hline \multirow{3}{*}{ Salary } & Pearson Correlation & $0.574^{* *}$ & $0.654^{* *}$ & 1 & $0.598^{* *}$ \\
\hline & Sig. (2-tailed) & 0 & 0 & - & 0 \\
\hline & $\mathrm{N}$ & 44 & 44 & 44 & 44 \\
\hline \multirow{3}{*}{ Retention } & Pearson Correlation & $0.487^{* *}$ & $0.579^{* *}$ & $0.598^{* *}$ & 1 \\
\hline & Sig. (2-tailed) & 0.001 & 0 & 0 & - \\
\hline & $\mathrm{N}$ & 44 & 44 & 44 & 44 \\
\hline \multicolumn{6}{|c|}{ **. Correlation is significant at the 0.01 level (2-tailed) } \\
\hline \multicolumn{6}{|c|}{ Model Summary } \\
\hline Model & $\mathbf{R}$ & R Square & Adjusted R Square & \multicolumn{2}{|c|}{ Std. Error of the Estimate } \\
\hline 1 & $0.655 a$ & 0.429 & 0.387 & \multicolumn{2}{|c|}{0.82721} \\
\hline \multicolumn{6}{|c|}{ a. Predictors: (Constant), Salary, O. Culture, Benefits } \\
\hline \multicolumn{6}{|c|}{ ANOVA $^{b}$} \\
\hline Variables & Sum of Squares & Df & Mean Square & $\mathbf{F}$ & Sig. \\
\hline Regression & 20.601 & 3 & 6.867 & 10.035 & $0.000^{\mathrm{a}}$ \\
\hline Residual & 27.371 & 40 & 0.684 & - & - \\
\hline Total & 47.972 & 43 & - & - & - \\
\hline \multicolumn{6}{|c|}{$\begin{array}{l}\text { a. Predictors: (Constant), Salary, O. Culture, Benefits } \\
\text { b. Dependent Variable: Retention }\end{array}$} \\
\hline \multicolumn{6}{|c|}{ Coefficients $^{a}$} \\
\hline \multicolumn{3}{|c|}{ Unstandardized Coefficients } & \multicolumn{3}{|c|}{ Standardized Coefficients } \\
\hline Model & B & Std. Error & Beta & $\mathbf{t}$ & Sig. \\
\hline (Constant) & -0.372 & 0.831 & - & -0.447 & 0.657 \\
\hline O. Culture & 0.244 & 0.293 & 0.129 & 0.833 & 0.41 \\
\hline Benefits & 0.44 & 0.26 & 0.282 & 1.689 & 0.099 \\
\hline Salary & 0.471 & 0.231 & 0.34 & 2.041 & 0.048 \\
\hline
\end{tabular}

Table 3: The responses of job satisfaction from 3.1-5. 


\section{The responses of job satisfaction from 3.1-5}

The results of 3.1-5 are fully significant. It means that organizational culture, benefits and salary has strong direct impact on job satisfaction. And therefore, employee retention is increased due to more satisfied employees. In this case all three hypotheses are accepted due to the significance level of the results (Table 3).

\section{Discussion}

\section{Future direction}

This study can be used in future with same and some other combinations of variables. These variables are the core variables in any time period these will remain same. Some other factors can be joined to have more accurate and specific results to any of these factors. For instance, organization culture can be further elaborated by the styles of management, employee's relations with peers, subordinates or bosses, power distance and gender discriminations etc. salary will remain the same. Benefits can be more diversified, like non-financial and financial benefits can be discriminated. Benefits can be categorized to conduct research that which category is affecting the employee retention most. Suggestions from employees can play an important role in this regard. Education and industrial both sectors can implement these steps to reduce employee turnover.

\section{Limitation}

This study has focused on only three independent and one intermediating variable, because these have direct relation with employee retention. Some other variables can also be taken as part of this study but they from one or another angle have direct or indirect relation with organizational culture, benefits and salary. We can say that these are the four key points in employee retention. Selection of other indirect factors can make the study more complicated and difficult to grasp the core purposes by having lot many justifications of various result sheets. Similarly, the more the variables the lengthier will be questionnaire, interview or survey. This will reduce the response rate. And ultimately the results will be disturbed.

\section{Conclusion}

After reviewing the literature, conducting questionnaires to get some fresh data to support our study, we have found that if organizational culture, benefits and salary are suitable enough to raise the job satisfaction. the employee retention will be high, and organizations can lead by having a competitive advantage of having more satisfied and retained workforce. So, if any organizations want to succeed in the market place it has to maintain desired levels of benefits, attractive salary packages, maintain a good organizational culture, and satisfy their employees as much as they can. This will increase the employee loyalty and higher retention rates.

\section{References}

1. Anis A, Rehman K, Rehman I, Khan MA, Afzal A (2011) Impact of organizational commitment on job satisfaction and employee retention in pharmaceutical industry. Afr J Bus Manage 5: 7316-7324.

2. Shoaib M, Noor A, Tirmizi SA, Bashir S (2009) Determinants of employee retention in telecom sector of Pakistan. Proceedings $2^{\text {nd }}$ CBRC, Pakistan.

3. Yang J (2009) Antecedents and consequences of job satisfaction in the hote industry. J Hosp Manage 29: 609-619.

4. Glance NS, Hogg T, Huberman BA (1997) Training and turnover in the evolution of organizations. Organ Sci 8: 84-96.

5. Mudor H, Tooksoon P (2011) Conceptual framework on the relationship between human resource management practices, job satisfaction, and turnover. J Econ Behav Stud 2: 41-49.

6. Alshammari MA, Aqied BA, Mawali H Al, Matalqa M (2016) What drives employee's involvement and turnover intentions: Empirical investigation of factors influencing employee involvement and turnover intensions. Int $J$ Manage Market 6: 298-306.

7. Kerr SA (1997) Retention of first-term and second-term marine corps enlisted personnel, Master's Thesis, Naval Postgraduate School, Monterey, CA.

8. Kossivi B, Xu M, Kalgora B (2016) Study on determining factors of employee retention. Open J Soc Sci 4: 261-268.

9. Ting $Y$ (1997) Determinants of job satisfaction of federal government employees. Public Pers Manage 26: 313-334. 